\title{
Analisa Visual Desain Sampul Album Rekaman Glenn Fredly: Romansa ke Masa Depan
}

\author{
Yulius Carlo Ariobimo Mangangantung ${ }^{1}, \mathrm{Zita} \mathrm{Nadia}^{2}$ \\ ${ }^{1}$ Program Studi Desain Komunikasi Visual, Universitas Pembangunan Jaya \\ Tangerang Selatan, Banten 15413, Indonesia \\ 2 Program Studi Desain Komunikasi Visual, Universitas Pembangunan Jaya \\ Tangerang Selatan, Banten 15413, Indonesia \\ Email korespondensi: zita.nadia@upj.ac.id
}

Received 30 December 2020, Revised 25 March 2021, Accepted 11 May 2021

\begin{abstract}
The design of the record album cover is a visual medium of the musician to the audience. The image of the musician can also showed from the album cover design. This research specifically focused on visual design of Glenn Fredly's record album 'Romance Into the Future', qualitative method approach is used in this research by using of visual analysis. Analysis is done by describing the design elements and the design principles applied to the album cover, in addition, the analysis is also obtained by doing a comparison of the visuals of Glenn Fredly's previous album. This research is useful to review album cover design with a visual approach that applied the principles of graphic design.
\end{abstract}

Keywords: Album Cover Design, Glenn Fredly, Pop Music

\begin{abstract}
Abstrak - Desain sampul album rekaman merupakan medium visual dari musisi kepada audiens. Citra musisi juga dapat terbentuk dari apa yang ada pada desain sampul album tersebut. Penelitian ini secara khusus fokus membahas visual desain sampul album rekaman Glenn Fredly 'Romansa Ke Masa Depan' sebagai bahan analisis, metode penelitian yang digunakan adalah kualitatif, dengan cara analisis visual. Analisa dilakukan dengan menjabarkan elemen desain dengan prinsip desain yang diterapkan pada sampul album ini, selain itu, analisa juga diperoleh dengan melakukan perbandingan dari visual album terdahulu Glenn Fredly. Penelitian ini bermanfaat untuk mengkaji desain sampul album dengan pendekatan visual yang sesuai dengan kaidah prinsip desain grafis.

Kata Kunci: Desain Sampul Album, Glenn Fredly, Musik Pop
\end{abstract}

\section{PENDAHULUAN}

Sepanjang perjalanan sejarah, musik telah berkembang dari awal peradaban manusia hingga di era modern ini. Kini musik terbagi dalam berbagai aliran musik. Salah satunya yang paling umum adalah musik populer. Musik populer atau lebih dikenal dengan istilah musik pop adalah salah satu aliran musik yang berkembang di seluruh dunia dan juga di Indonesia dimulai dari tahun 1950-an. Musik pop juga mengacu pada musik yang populer pada pasar atau disebut juga musik mainstream.

Pada industri musik di Indonesia secara umum terdapat dua pihak yang mengatur proses pembuatan musik, yaitu label mayor dan label independen. Baik label mayor maupun independen memiliki prosedur yang serupa dalam proses pembuatan musik untuk musisi naungannya. Proses pembuatan musik yang diatur oleh label adalah produksi musik, konten lagu, pemasaran, promosi hingga desain sampul album rekaman.

Desain sampul album rekaman memiliki peranan penting dalam sebuah karya musik. selain karya musik itu sendiri memiliki pesan yang disampaikan, lewat desain sampul album rekaman, musisi turut menyampaikan pandangan mereka tentang makna lagu, atau bahkan pesan maupun kritik tentang sebuah keadaan. Menurut Respati (2016) desain sampul album rekaman dapat menjadi sebuah medium dari musisi kepada audiens. Citra musisi pun dapat dibentuk dari desain sampul album rekaman, bagaimana visual membentuk citra musisi melalui apa yang ada pada desain sampul album rekaman.

Salah satu musisi yang memiliki peran penting dalam musik Indonesia ialah Glenn Fredly. Ia adalah seorang musisi pop/R\&B berdarah Ambon dengan sejumlah karya populer dari tahun 1990-an hingga sekarang. Glenn Fredly memiliki pesan-pesan tentang kasih terhadap sesama melalui lagu-lagu romantis yang ia ciptakan. Glenn Fredly juga memperjuangkan rakyat di Timur Indonesia lewat karya-karyanya, yang berisikan pesan kemanusiaan.

Setelah sembilan tahun tidak merilis album rekaman, pada tahun 2019 Glenn Fredly 
meluncurkan album rekaman terbarunya bertajuk 'Romansa Ke Masa Depan' yang bercerita tentang sebuah harapan untuk masa depan dari sudut pandang seorang Glenn Fredly. Desain sampul album rekaman yang dirancang oleh Yulius Carlo dengan fotografi oleh Crist Tarigan hadir dengan nuansa ' 80 -an. Menunjukkan potret sebuah pohon bakau di pantai Walakiri, Sumba, serta desain judul album rekaman bergaya neon ala ' 80 -an. Pohon bakau tersebut melambangkan sebuah harapan untuk masa depan untuk Indonesia.

Desain sampul album rekaman ini juga memiliki gaya desain yang berbeda dibanding album rekaman terdahulunya mulai dari konsep, fotografi hingga gaya desain sehingga peneliti bertujuan untuk mengkaji aspek-aspek visual yang terdapat di dalam desain album rekaman 'Romansa Ke Masa Depan'.

\section{METODE PENELITIAN}

Penelitian ini membahas gaya desain sampul album rekaman Glenn Fredly 'Romansa Ke Masa Depan' menggunakan metode penelitian kualitatif. Penelitian kualitatif menurut Creswell (2014), adalah penelitian yang digunakan untuk menggambarkan, dan menjelaskan kualitas atau keistimewaan dari pengaruh sosial yang tidak dapat diukur atau digambarkan melalui penelitian kuantitatif, baik dari melakukan pengamatan, analisis konten, etnografi dan pendekatan lainnya.

Penelitian ini menggunakan pendekatan analisis visual, sebuah pendekatan untuk menguraikan serta mengintrepretasi sebuah karya visual (Soewardikoen, 2019). Proses interpretasi sebuah karya visual membutuhkan proses dan tahapan yang masuk akal. Terdapat empat tahapan dalam analisa visual (Edmund dalam Soewardikoen, 2019):

1. Deskripsi: Pada tahapan ini peneliti melihat unsur visual apa saja yang terlihat, seperti warna, ilustrasi, tipografi, tata letak dan lainnya. Unsur visual dijabarkan secara denotatif.

2. Analisis: Pada tahapan ini bisa dilihat seperti apakah hubungan antar unsur visual yang ada.

3. Interpretasi: Tahapan analisis sudah membahas hubungan antar unsur visual, maka pada tahapan ini dilihat apakah simbol dan makna metaforanya.

4. Penilaian: Pada tahap ini dilakukan proses penilaian visualisasi secara keseluruhan dan kualitas pesan yang disampaikan.

Studi literatur dengan menggunakan buku dan jurnal dengan topik terkait digunakan untuk memperkuat analisa visual dari desain sampul album, selain itu penelitian juga dilengkapi dengan data visual.

Fokus penelitian ini adalah pada desain sampul album rekaman Glenn Fredly 'Romansa Ke Masa Depan' dengan pembanding dari desain sampul album rekaman Glenn Fredly terdahulu dari tahun
1998 hingga 2010 dan album rekaman kolaborasi Glenn Fredly dan The Bakuucakar tahun 2012.

\section{KAJIAN PUSTAKA}

Kajian pustaka berfungsi untuk menjadi landasan teori peneliti saat menganalisa visual pada desain album rekaman 'Romansa Ke Masa Depan'. Kajian pustaka membantu pada tahapan deskripsi dan analisa. Di tahapan deskripsi dibutuhkan unsur visual yang terlihat, sedangkan pada analisa dibutuhkan hubungan antar elemen visual.

Aspek visual dari sebuah desain pada umumnya dibagi menjadi aspek berwujud dan aspek abstrak. Aspek berwujud merupakan aspek yang dapat dilihat secara langsung seperti elemen desain atau unsur desain. Aspek abstrak merupakan prinsip-prinsip desain yang mengatur peletakan elemen visual sehingga terjadinya sebuah desain yang harmonis akibat adanya interaksi antara elemen desain, berikut paparan dari elemen visual dan prinsip desain:

\section{Elemen Desain}

Elemen desain atau unsur desain adalah, bagian atau elemen-elemen visual pembangun sebuah karya desain, terdapat banyak elemen desain yang dapat digunakan, diantaranya menurut Poulin (2011) adalah:

1. Garis: dapat bermakna sebagai alur yang dapat ditelusuri. Penggunaan garis dalam desain dapat dilihat secara langsung atau dilihat dalam bentuk implikasi.

2. Bentuk: bentuk ruang atau kontur, atau sebuah konfigurasi dari sebuah objek, bentuk juga dapat menunjukkan struktur dari sebuah objek.

3. Warna: sebuah fenomena cahaya atau persepsi visual yang dapat membuat audiens membedakan dari satu hal dengan hal lainnya. Warna juga dapat mencerminkan temperatur, beberapa warna terkesan lebih hangat seperti warna merah, kuning dan oranye, dan terdapat warna yang terkesan lebih dingin seperti biru dan hijau.Warna di dalam desain komunikasi visual juga memiliki makna subjektif untuk menyampaikan pesan kepada audiens.

4. Tipografi: merupakan penggunaan dan pemilihan typeface baik dari segi gaya, tampilan dan peletakan. Desainer grafis dapat memanfaatkan tipografi tidak hanya dari fungsi dasar sebagai elemen desain, namun dapat juga untuk menyampaikan pesan tertentu dengan menggunakan kesan dari yang dimiliki dari sebuah typeface.

Terdapat elemen desain lainnya yang disebutkan oleh Poulin, seperti titik dan cahaya, namun yang digunakan adalah yang terkait dengan penelitian ini. Elemen desain berguna untuk menjabarkan tahap satu dari analisis visual, yaitu tahapan deskripsi. 


\section{Prinsip Desain}

Prinsip desain adalah hubungan yang berkerja dari terbentuknya interaklsi antar elemen di dalam sebuah desain, beberapa prinsip desain yang bisa kita temui dalam sebuah desain menurut Anggraini dan Nathalia (2018) adalah:

1. Keseimbangan (Balance): merupakan hubungan antar unsur desain dalam pembagian yang imbang secara optik, pembagian merata dapat dikenal dengan keseimbangan simetris dan pembagian yang tidak merata (sama persis) disebut dengan keseimbangan asimetris.

2. Irama (Rythm): merupakan sebuah prinsip kerja dari pengulangan atau penyusunan elemen desain yang berulang.

3. Penekanan (Emphasis): Prinsip desain dimana terdapat penekanan dari elemen desain sehingga lebih menonjol dari elemen lainnya, baik dengan menggunakan kontras, isolasi objek atau penempatan.

4. Kesatuan (Unity): Prinsip desain yang menunjukkan harmoni antar elemen desain sehingga terlihat menjadi sebuah kesatuan karya desain.

Prinsip desain yang telah dijabarkan menjadi bagian tahapan dua dari analisis visual yaitu tahapan analisis, dimana dijabarkan hubungan antara unsur visual yang ada pada desain sampul album 'Romansa Ke Masa Depan'.

\section{HASIL PENELITIAN DAN ANALISIS}

Hasil dari penelitian ini menggunakan pendekatan analisis visual, untuk menganalisa visual yang terdapat dari desain sampul album 'Romansa Ke Masa Depan'. Analisa visual akan dilakukan melalui empat tahapan sesuai dengan yang dikemukakan oleh Soewardikoen (2019), yaitu tahapan deskripsi, analisis, interpretasi dan penilaian. Keempat tahapan ini dibutuhkan untuk menapatkan interpreasi analisa visual yang baik.

Visual yang dianalisa terdiri dari elemen visual yang dianalisa pada tahap deskripsi dan prinsip desain yang digunakan pada tahap analisis, dan dilanjutkan dengan tahapan interpretasi dan penilaian, berikut adalah hasil analisis dari setiap tahapan analisa visual:

\section{Tahap 1: Deskripsi}

Pada tahapan ini peneliti mengkaji elemen desain secara denotatif di dalam desain sampul album 'Romansa Ke Masa Depan', berikut adalah tampilan dari objek penelitian:

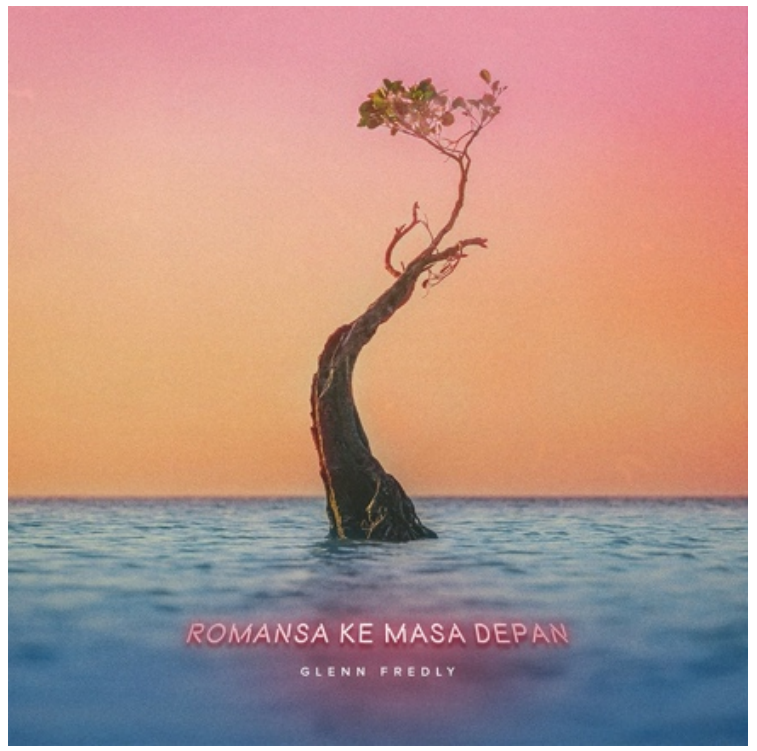

Gambar 1 Desain sampul album rekaman Glenn Fredly 'Romansa Ke Masa Depan'

Secara visual desain sampul album rekaman Glenn Fredly 'Romansa Ke Masa Depan' berbeda dibanding desain sampul album rekaman Glenn Fredly terdahulu mulai dari konsep, gaya fotografi hingga warna. Album rekaman 'Romansa Ke Masa Depan' menghadirkan konsep bernuansa '80-an diikuti gaya fotografi pemandangan alam khas Sumba dengan warna yang cerah namun lembut dengan penambahan grafis judul bergaya neon khas ' 80 -an.

\section{Warna}

Warna yang digunakan pada album album adalah gabungan dari temperatur warna hangat seperti merah muda, dan oranye, juga temperatur warna dingin dari biru laut (Hornung, D. 2005) berupa gradasi yang memvisualisasikan semburat langit dan laut sesuai dengan referensi nuansa yang ingin dicapai dan tema tropikal '80-an. (Kate, 2011).

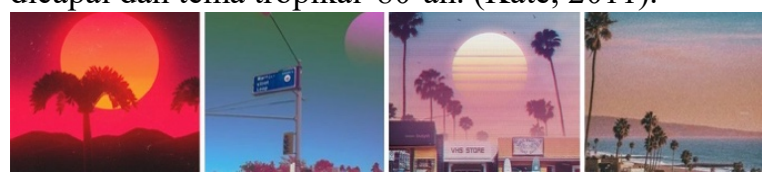

Gambar 2 Referensi desain sampul album rekaman 'Romansa Ke Masa Depan'

Secara psikologi warna, penggunaan warna yang digunakan juga terkesan lembut, dominan dengan tone hangat ke arah merah jambu sehingga sesuai dengan nama album yang diwakili yaitu 'Romansa Ke Masa Depan' yang terdapat persamaan kata cinta di dalamnya. 
Tipografi

Beon Typeface

AA BB CC DD EE

1234567890

Proxima Nova

$\mathrm{Aa} \mathrm{Bb} \mathrm{Cc} \mathrm{Dd} \mathrm{Ee}$ 1234567890

Gambar 3 Typeface yang digunakan pada album'Romansa Ke Masa Depan'

Typeface yang digunakan adalah Beon untuk judul dan Proxima Nova untuk nama. Penggunaan jenis huruf pada judul bergaya neon disesuaikan dengan tema yang mengusung nuansa ' 80 -an. Pada nama Glenn Fredly menggunakan font san-serif dengan ukuran lebih kecil dibanding judul utama. Sedangkan pada judul penggunaan font bergaya neon diberikan efek menyala (glow) layaknya lampu neon sign sehingga mendapatkan kesan khas 80-an.

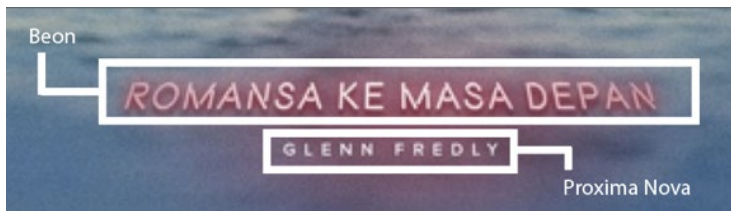

Gambar 4 Penggunaan typeface pada album album'Romansa Ke Masa Depan'

Perbandingan Gaya Visual Album Glenn Fredly

Jika menarik waktu mundur ke tahun 1998 hingga 2012, jelas terlihat pengaruh gaya pop mainstream pada desain sampul album Glenn Fredly. Sampul album tersebut menggunakan teknik pengolahan foto digital dengan tampilan warna cukup mencolok yang menampilkan wajah atau foto potret Glenn Fredly pada beberapa sampul album serta penggunaan logo dan tipografi pada judul album yang cenderung ekspresif (Basuki, M., Lasiman, L., \& Widjoyo, C, 2009).

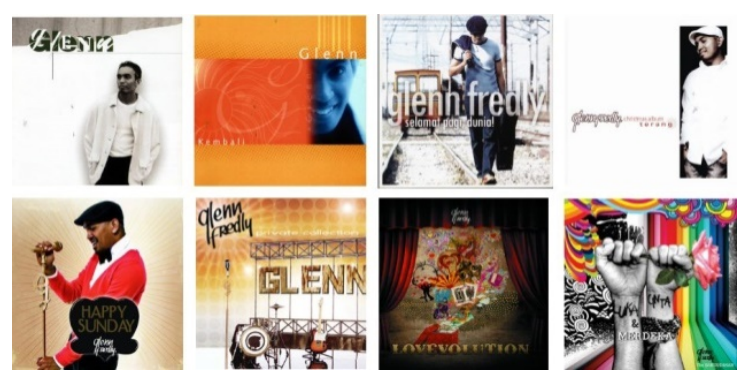

Gambar 5 Kumpulan desain sampul album rekaman Glenn Fredly tahun 1998-2012
Sedangkan jika kita perhatikan desain sampul album rekaman 'Romansa Ke Masa Depan', memiliki perbedaan yang cukup signifikan. Meskipun sama menggunakan teknik pengolahan foto digital, namun foto musisi Glenn Fredly tidak dihadirkan seperti 3 album sebelumnya.

'Romansa Ke Masa Depan' juga tidak menggunakan elemen desain yang ekspresif, namun kali ini terfokus untuk menggunakan elemen desain yang sederhana dan modern, dan fokus utama terdapat pada foto pohon bakau yang menjadi penekanan visual pada album ini. Penggunaan logo juga digantikan dengan nama musisi yang berada di bawah judul album.

Warna yang digunakan juga termasuk lebih lembut jika dibandingkan dengan warna dari albumalbum Glenn Fredly sebelumnya yang terlihat pada Gambar 5. Warna dari album romansa ke masa depan diperoleh dari pengolahan teknik foto digital, untuk mencapai kesan yang diinginkan.

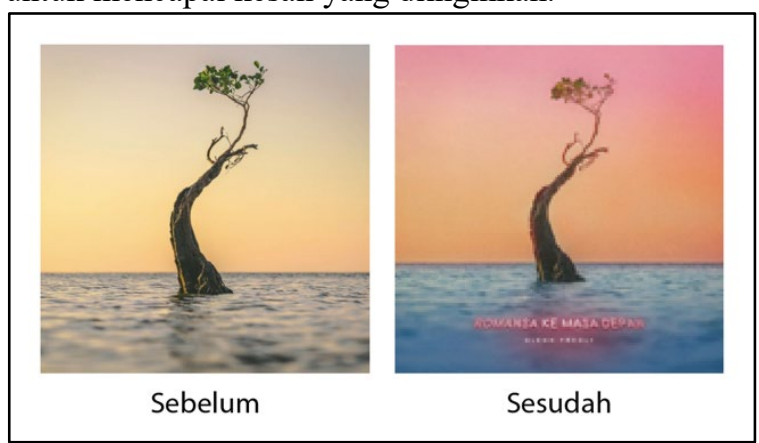

Gambar 6 Perbandingan pengolahan warna foto

Penggunaan tipografi untuk penulisan nama musisi juga memiliki perbedaaan yang signifikan, jika kita perhatikan pada 5 album terakhir Glenn Fredly menggunakan font dengan tipe yang terkesan seperti tulisan tangan yang memiliki kesan lebih klasik jika dibandingkan dengan font Proxima Nova yang digunakan pada bagian nama musisi di album 'Romansa Ke Masa Depan', yang memiliki kesan yang lebih modern dan sederhana.

Perbedaan gaya desain inilah yang membuat desain album 'Romansa Ke Masa Depan' menjadi sebuah inovasi baru dalam perjalanan desain album album Glenn Fredly.

\section{Tahap 2: Analisis}

Pada tahapan ini peneliti mengkaji hubungan antara elemen-elemen desain yang digunakan dalam album 'Romansa Ke Masa Depan' dengan menggunakan prinsip desain grafis. Desain sampul album rekaman Glenn Fredly 'Romansa Ke Masa Depan' sesuai dengan prinsip desain grafis, yaitu menerapkan kesederhanaan, keseimbangan, kesatuan, penekanan dan irama. Prinsip kesederhanaan dapat dilihat dari komposisi foto dan teks yang terdapat white space (ruang kosong) yang memberikan kesan bersih, lega dan terdapat ruang bernapas untuk penglihatan audiens. 


\section{Keseimbangan (Balance)}

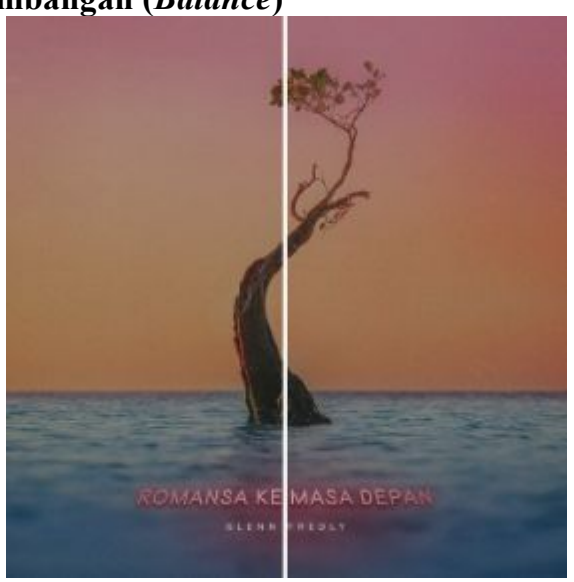

Gambar 7 Keseimbangan desain sampul album 'Romansa Ke Masa Depan’

Selain kesederhanaan, prinsip keseimbangan juga jelas terlihat dari komposisi fotonya. Jarak yang seimbang antara pohon, langit serta laut. Prinsip kesatuan juga diterapkan dari keutuhan seluruh elemen pada desain sampul ini. Sedangkan penekanan dalam sampul album rekaman ini terletak pada objek pohon bakau yang berdiri di atas lautan tepat di tengah karya desain ini, berikut penjabaran secara detail dari prinsip desain yang ada pada album album 'Romansa Ke Masa Depan'.

Keseimbangan pada sampul album ini merupakan jenis keseimbangan simetris, karena dapat dilihat dari jarak antar elemen desain, ukuran, dan penempatan elemen cenderung sama pada tiap sisi, terutama pada pembagian sisi kanan dan kiri. Terutama dari letak penempatan image pohon bakau dan peletakan nama album serta nama musisi yang berada tepat di tengah album.

\section{Irama (Rythm)}

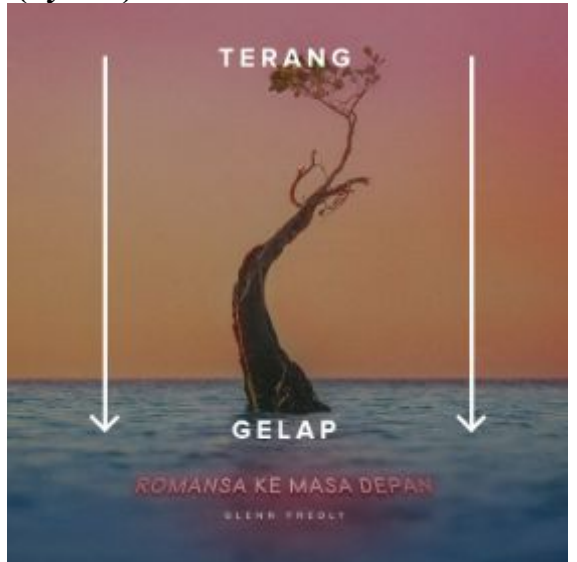

Gambar 8 Irama pada desain sampul album 'Romansa Ke Masa Depan'

Penerapan prinsip irama/ritme pada elemenelemen desain album album, terdapat pada penggunaan gradasi warna antara warna latar dan pohon yang digambarkan dalam peralihan warna terang menuju gelap. Pada umumnya audiens melihat terang terlebih dahulu sebelum gelap, karena warna terang bisa dilihat lebih mudah akibat lebih menarik perhatian.

Ritme ini juga terjadi akibat adanya perbedaan terang jika dua warna disandingkan, beberapa warna akan terasa lebih terang jika dibandingkan dengan warna lainnya (Holtzschue,2017) dalam hal ini warna langit terasa lebih cerah jika dibandingkan dengan warna laut, sehingga mata audiens tertuju dari langit menuju laut.

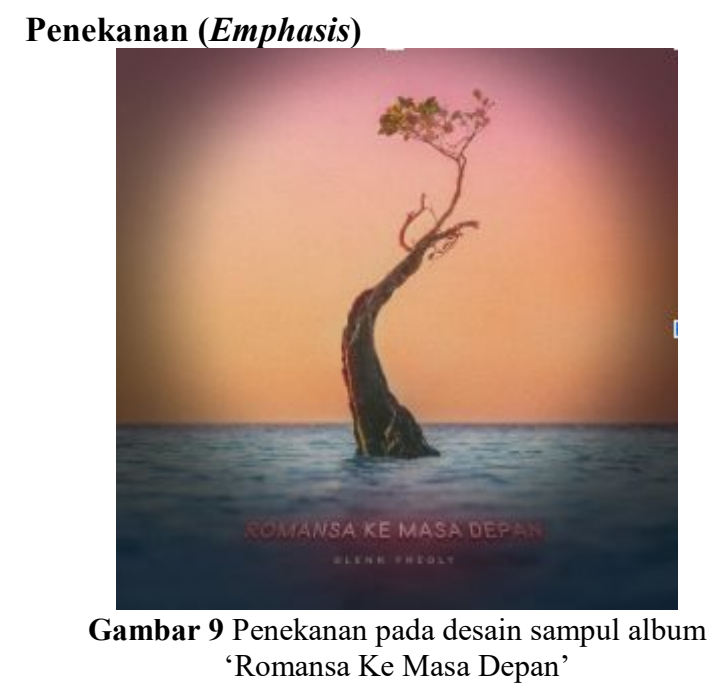

Prinsip desain berikutnya adalah penekanan (emphasis), penekanan pada desain sampul album ini terletak pada pemanfataan fokus di foto pohon bakau yang berdiri diatas laut, dengan menjadikannya fokus pusat perhatian nan menarik pada karya desain ini. Dapat dilihat dari, peletakan yang berada di tengah-tengah karya desain, selain itu penekanan juga dapat dilihat dari segi ukuran. Ukuran pohon yang jika diperhatikan memiliki proporsi lebih besar dari elemen desain lainnya, serta adanya kontras antara warna pohon dan warna latar pada karya desain, sehingga mata audiens terfokus pada bagian tengah sampul album.

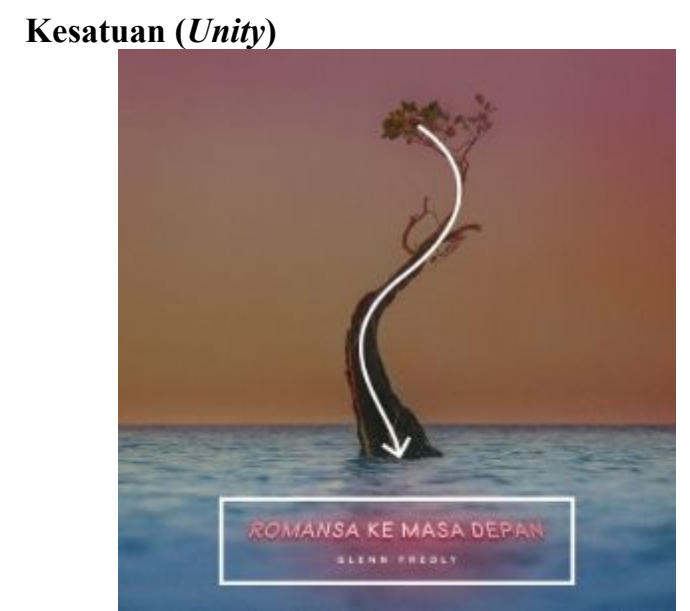

Gambar 10 Alur baca yang mengikat kesatuan elemen desain sampul album 'Romansa Ke Masa Depan' 
Kesatuan adalah prinsip desain dimana ketika audiens melihat sebuah karya desain, audiens melihat satu karya yang utuh. Kesatuan bisa didapatkan dengan membuat hubungan antar elemen desain seperti pada alur baca yang terjadi akibat sususan tata letak elemen desain. Alur baca mengikat elemen desain menjadi satu kesatuan.

Tipografi judul diatur secara sistematis untuk mengarahkan prioritas audiens membaca judul diikuti dengan nama Glenn Fredly. Alur baca tersebut juga didukung oleh bentuk foto pohon yang meliuk tepat diatas judul, dan mengarahkan mata audiens langsung kepada judul dan nama musisi seperti pada Gambar 10. Selain itu kesatuan juga didapatkan dengan konsistensi penggunaan warna dalam desain yang masih sesuai dengan tema yang ingin dicapai, dalam bentuk nuansa tropikal tahun 80 -an yang diwujudkan dalam warna merah muda, oranye dan biru laut.

\section{Tahap 3: Interpretasi}

Pada tahapan ini peneliti mengkaji makna simbolis dan metafora yang terdapat di dalam album album 'Romansa Ke Masa Depan'. Pada karya desain kita dapat melihat bahwa objek utama adalah pohon bakau yang berada di tengah lautan.

crist.tarigan • Follow
Jakarta, Indonesia
terbaru @glennfredly309. Salah
satunya ketika foto cover albumnya
menggunakan foto yang saya hasilkan.
Sharing:
Sebenernya GF dateng dengan konsep
yang keren (bukan seperti foto diatas)
kita diskusi beberapa kali ttg cover
album. Tapi seketika konsep yang udah
kita rancang berubah di lokasi
shooting trakhir, dan @glennfredly309
punya ide ttg cover album yang
pengen terlihat "alam yang berbeda,
suatu tempat yg unik dan nggak biasa
yang akan mnjadi masa depan, dan
melbangkan HOPE" Dan seneng
banget ktika GF dan management
memutuskan utk pakai foto pohon ini.
Moment2 ide muncul ada di slide ke2.
Sekian dA
.

Gambar 11 Keterangan makna pohon bakau pada album 'Romansa Ke Masa Depan'

Menurut Glenn Fredly pohon bakau yang menjadi objek utama memiliki makna untuk harapan di masa depan seperti yang dituliskan di laman Instagram Crist Tarigan fotografer untuk pohon bakau yang digunakan pada album 'Romansa Ke Masa Depan' Harapan menurut peneliti juga bisa disimbolkan dari sifat pohon yang selalu tumbuh dari masa ke masa. Alam yang unik juga terlihat dari pohon yang seolah tumbuh di tengah laut sendirian, yang menjadi sebuah habitat unik, seperti masa depan yang belum diketahui dan bisa menjadi dunia yang benar-benar baru dan unik.

\section{Tahap 4: Penilaian}

Secara keseluruhan jika dilihat album 'Romansa Ke Masa Depan', sudah menyusun elemen-elemen desain yang ada dan menggunakan prinsip desain dalam proses perancangannya.Elemen desain yang digunakan juga sudah mampu untuk mencapai pesan yang dituju baik dari mewakilkan tema tropikal tahun 80-an, dan untuk mewakilkan pesan dari musisi Glenn Fredly yang berjudul 'Romansa Ke Masa Depan', seperti warna yang dipilih untuk mewakili tema romansa. Pesan juga dapat disampaikan melalui pemilihan objek utama di dalam desain yang memiliki makna metafora yang mendukung judul dari album yang diwakilkan kepada audiens.

\section{KESIMPULAN}

Desain sampul album rekaman Glenn Fredly 'Romansa Ke Masa Depan' merupakan album terbaru dan terakhir dari Glenn Fredly. Konsep dan nuansa yang disampaikan pada album memiliki perbedaan cukup signifikan dibanding album terdahulunya. Tema '80-an yang diangkat menjadikan desain sampul album ini tampil beda dengan dukungan dari prinsip-prinsip desain yang diterapkan pada desain sampul album ini. Dengan penekanan pada foto pohon bakau, menjadikan album ini memiliki daya tarik dan alur baca yang tepat. Pemilihan warna dan tipografi juga disesuaikan dengan tema dan mendekati referensi yang akan dicapai, membuat desain sampul album rekaman Glenn Fredly 'Romansa Ke Masa Depan' tampil beda dan inovatif.

\section{UCAPAN TERIMA KASIH}

Penulis mengucapkan terima kasih kepada Glenn Fredly selaku musisi yang telah mempercayakan karya visual kepada penulis, Kinasih Sarawati sebagai supervisor dan koordinator, Imam Syafi'i sebagai partner tim, Crist Tarigan sebagai fotografer dari album 'Romansa Ke Masa Depan', dan kepada pihak Bumi Entertainment.

\section{DAFTAR PUSTAKA}

Anggraini, L. \& Nathalia, K. (2018). Desain Komunikasi Visual. Bandung: Penerbit Nuansa.

Basuki, M., Lasiman, L., \& Widjoyo, C. (2009). Desain Grafis Gaya Pop: Studi Kasus Sampul Album Rekaman Musisi Indonesia. Nirmana, 8(2), pp. 7383. doi:10.9744/nirmana.8.2.pp. 73-83

Creswell, J. (2014). Research Design: Qualitative, Quantitative, and Mixed Methods Approaches. California: Sage.

Holtzschue, L. (2017). Understanding Color: An Introduction for Designers. New Jersey: John Wiley \& Sons, Inc.

Hornung, D. (2005). Colour: a workshop for artists and designers. Laurence King Publishing. 
Kate. (2011) 1980s Graphic Design Styles. Diakses melalui https://mirror80.com/2011/11/1980s-graphicdesign- styles/

Poulin, R. (2011). The language of graphic design:An illustrated handbook for understanding fundamental design principles. Massachusetts: Rockport Publishers.

Respati, Y. R. (2016). Komunikasi Ideologi Band Indie Melalui Desain Cover Album Studi Kasus: The Sigit. Jurnal Dimensi DKV Seni Rupa dan Desain, 1(2), 117-136.

Soewardikun, D.W. (2019). Metodologi Penelitian Desain Komunikasi Visual.Yogyakarta: PT Kanisius. 